\title{
ESTADO CONSTITUCIONAL ECOLÓGICO: EDUCAÇÃO, PROTEÇÃO E O RECONHECIMENTO DOS DIREITOS DOS POVOS INDÍGENAS
}

\section{THE CONSTITUTIONAL ECOLOGICAL STATE: EDUCATION, PROTECTION AND RECOGNIZATION OF INDIGENOUS PEOPLE RIGHTS}

\author{
${ }^{1}$ Francisco Ercílio Moura \\ ${ }^{2}$ Antônio Torquilho Praxedes
}

\section{RESUMO}

Trata-se do tema do Estado Constitucional Ecológico e dos atores sociais capazes de construílo, diante de uma perspectiva intercultural que concretize a proteção do meio ambiente natural e social. Na construção deste trabalho, aborda-se o papel da conscientização social que esteja fundamentada no diálogo entre as diferentes perspectivas socioculturais, com ênfase à inserção da cosmovisão dos povos autóctones nas políticas públicas de ensino.

Palavras-chave: Constitucionalismo. Ecologia. Povos indígenas.

\begin{abstract}
This research focus on the theory of Constitutional Ecological State and its social actors enabled to contribute to its formulation, starting from an intercultural perspective that could guarantee its natural and social environmental protection. In doing so, one should realize that this project demands a restructure on the social conscience, capable of promoting a widen sociocultural perspective on the social dialogue, with the active participation of the indigenous people on Educational Public Policy.
\end{abstract}

Keywords: Constitutionalism. Ecology. Indigenous People.

\footnotetext{
${ }^{1}$ Doutor em Ciências Sociais pela Universidade Federal do Ceará - UFC, Ceará (Brasil). Professor nos cursos de graduação e pós-graduação de Direito pela Faculdade Leão Sampaio - UNILEÃO, Ceará (Brasil).

E-mail: emoura25@outlook.com

${ }^{2}$ Mestre e especialista em Ciências Jurídico-Comunitárias pela Universidade de Coimbra - UC, Coimbra (Portugal). Coordenador e professor dos cursos graduação e pós-graduação em Direito pela Faculdade Christus UNICHRISTUS, Ceará (Brasil). E-mail: poscoorddireito01@unichristus.edu.br
} 


\section{INTRODUÇÃO}

O tema deste trabalho consiste na abordagem sobre as questões epistemológicas relacionadas com a construção de uma subjetividade intercultural sobre o meio ambiente, que seja capaz de concretizar um projeto político institucional para a formação de um Estado Constitucional Ecológico no Brasil. Vez que esse paradigma estatal tem por objetivo garantir um meio ambiente equilibrado para as futuras gerações (CANOTILHO, 2001), então, é preciso um diálogo intercultural que promova uma conscientização entre todos os setores sociais que compõem à população brasileira. Para essa construção, torna-se necessário rever o atual estágio do processo de acumulação capitalista, frente aos desgastes que ele provoca no meio ambiente e que impactam nas relações sociais, a fim de viabilizar uma proposta alternativa que edifique novos valores ao atual modelo vigente de relações de produção de bens e serviços.

Diante dessa tarefa, foi necessário traçar pontos de conexão entre o âmbito político, econômico e jurídico, com o objetivo de formar um estudo interdisciplinar apto a discutir o tema da proteção ambiental, participação dos povos indígenas e regulação do mercado produtivo. Para atingir esse objetivo, lançou-se mão do método de investigação de revisão bibliográfica e documental, embasado na teoria crítica social para formar uma leitura dialética e dialógica, na perspectiva de resgatar as particularidades que caracterizam os universos sociais envolvidos na questão ambiental.

Este trabalho de pesquisa combina aspectos qualitativos e quantitativos, a partir do estudo dos casos selecionados na Política Nacional de Educação Ambiental, nomeadamente na Conferência Nacional Infanto-juvenil pelo Meio Ambiente (CNIJMA), tendo por campo de análise os trabalhos produzidos pelos docentes cearenses - com o cuidado de não se promover uma leitura generalizada, a partir de um caso regional. Serão apresentadas as experiências e as narrativas de vida dos atores sociais, a fim de entender o conteúdo informacional dos trabalhos apresentados na Conferência, que permitam reconstruir fatos relevantes e identificadores de suas identidades culturais relacionados ao meio ambiente (GIL, 2009).

Conceitua-se que esse material contém a perspectiva dos professores na questão da defesa ecológica e, portanto, integra a formação dos conhecimentos dos estudantes das escolas 
públicas participantes da Conferência; bem como a perspectiva dos povos originários, acerca da mesma questão ${ }^{3}$.

A pesquisa foi quantitativa e qualitativa. $\mathrm{Na}$ sua dimensão quantitativa, ela tentou revelar quantos projetos incorporaram o discurso autóctone sobre a preservação ambiental. Para tanto, foi necessário estruturar uma dimensão qualitativa, visto que a investigação se depara com um tema social de relevante importância e que comporta "[...] o universo dos significados, dos motivos, das aspirações, das crenças, dos valores e das atitudes" (DESLANDES, GOMES e MINAYO, 2009, p. 21). Em outras palavras, a análise da percepção sobre a proteção do meio ambiente albergou diferentes perspectivas, dentro de uma realidade partilhada entre seres humanos, onde representações e intencionalidades que não podem ser reduzidos a valores quantitativos. Os atores sociais participantes da pesquisa foram os professores das escolas públicas participantes do IV CNIJMA e os representantes dos povos autóctones da região onde as escolas se localizam, com vistas a assegurar a representatividade dos sujeitos da pesquisa (GIL, 2009).

As informações foram analisadas por meio da triangulação de dados e de fontes (DESLANDES, GOMES e MINAYO, 2009, p. 79-80), com a finalidade de convergir os dados coletados, para verificar a consistência das informações, tendo por base as distintas fontes utilizadas.

A hipótese que sustenta este trabalho consiste na percepção acerca da necessidade de uma interlocução entre os diversos atores públicos e privados que compõe a sociedade multicultural brasileira, na busca de uma democracia ambiental participativa, construída a partir da noção de interculturalidade. Esse modelo participativo estaria em consonância com o paradigma de Estado Constitucional Ecológico atualmente discutido, pois poderia incorporar formas alternativas de percepção do meio ambiente, que poderiam ainda ser resgatadas através do diálogo social entre os povos originários e os ocidentalizados, numa abordagem contra hegemônica, de visibilização de suas demandas e de seus projetos de vida (LOWY, 1978; FREIRE, 1979, 1982, 1996; SOUSA SANTOS, 2002a; QUIJANO, 2005).

Outra hipótese é a de que a inserção da cosmovisão dos povos autóctones na temática ambiental, com o fito de efetivar a proteção do meio ambiente às futuras gerações autóctones, promove o interculturalismo (SOUSA SANTOS; NUNES, 2003; ŻIŻEK, 2003). Para que isso se verifique, é preciso uma análise da interlocução desses atores, no contexto da educação

\footnotetext{
${ }^{3}$ É preciso descobrir se os autores desses projetos se autodefinem como "indígenas", ou se assumem como pertencentes a outra categoria étnico-racial.
} 
ambiental, com o intuito de se verificar como está sendo processada a construção desses saberes, e de que forma eles integram os programas de conscientização ambiental nas escolas de ensino fundamental (SOUSA SANTOS, 2002b, 2008).

\section{O SISTEMA PRODUTIVO E A REGULAMENTAÇÃO CONSTITUCIONAL}

O processo de acumulação capitalista encontra-se marcado pela busca crescente de recursos naturais para dar vazão ao processo de transformação produtiva e de acumulação ampliada do capital, mediante a elaboração de novos produtos industriais (MARX, 2007). Em contraste, nas economias campesinas, o foco da acumulação privilegiava uma empatia com o próprio processo natural de geração e recriação desses recursos naturais, que eram reabsorvidos pelo processo metabólico natural (SMITH, 1988). O sistema produtivo capitalista industrializante dá lugar aos novos processos de transformação das matérias primas que, processadas e gerando mais valia, criam subprodutos que se convertem: (1) em lixo e, consequentemente, em poluição e (2) no deslocamento do eixo social campo-cidade (LOWY, $1988)^{4}$. Assim, torna-se inexorável o desgaste ambiental promovido pela transferência desses recursos do campo para a cidade. Igualmente, se for considerado o atual estágio de disseminação desse modelo no planeta - facilitado pelo fluxo de capital e de empresas ao redor do globo, com amparo nas novas formas tecnológicas de comunicação e produção (SANTOS, 2006) -, salta aos olhos a percepção de que esse sistema se converteu numa autêntica força geológica a imprimir mudanças climáticas e a alterar as dinâmicas de absorção e recombinação de elementos orgânicos e inorgânicos 5 .

Diante dessas transformações socioeconômicas, a teoria do Estado Constitucional Ecológico (termo cunhado por Rudolf Steinberg, na obra "Der Ökologische Verfassungsstaat",

\footnotetext{
${ }^{4}$ Convém esclarecer que, no processo de modernização liberal do século XIX, diretamente associado à estruturação do paradigma Estado-nação - industrialização, instalação do ensino público e outras características modais da democracia liberal -, os arranjos da ordem social institucionalizada devem ser compreendidos como um construto social, no qual o conflito pela inclusão de minorias étnicas só começou a ser discutido na segunda metade do século XX (TIRYAKIAN, 2003).

${ }^{5}$ Nesse aspecto, é interessante observar que houve uma apropriação da natureza pelo atual sistema mundo de produção capitalista, com sérias implicações na seara ambiental. É notório que essa apropriação desenfreada está diretamente ligada à ação humana no trabalho, na interação do ser humano com o meio ambiente natural e na produção dos objetos socioculturais (SMITH, 1988). Fazendo referência direta ao conceito de "metabolismo" (Stoffwechesel) de Karl Marx, o sociólogo norte-americano John Bellamy Foster (2000, p. 141) explica que o processo de trabalho, como interação entre humanidade e natureza, é a atividade pela qual os seres humanos intermediam, normatizam e controlam o metabolismo entre a humanidade e o espaço natural.
} 
publicada em 1998) emerge como uma proposta teórica voltada ao desenvolvimento sustentável. Essa concepção parte de uma reafirmação do Estado como o paradigma zero de organização política, pautado por uma democracia republicana regulada pelo Direito Constitucional e com uma finalidade específica: a preservação do meio ambiente sociocultural e natural, em busca de um modelo de democracia sustentada (CANOTILHO, 2001). Convergem, nesse conceito, as noções de representatividade política e de participação popular, normatizada na atual Constituição republicana brasileira vigente, mas que ainda demandam tanto um adequado regramento infraconstitucional, quanto novas formas de interpretação do fenômeno jurídico, que ultrapassem as limitações teóricas que estruturam o modelo clássico de Estado de Direito, no qual a predominância do sistema partidário de representação política arruína a democracia (BONAVIDES, 2000). Em substituição a esse modelo oligárquico partidário arcaico e não democrático, o cidadão deve partir em busca da efetivação do princípio jurídico-político da dignidade da pessoa humana e de novas formas de promoção da justiça social, que tem na participação popular o fundamento de uma democracia construída sobre bases de amplos setores sociais (BONAVIDES, 2001).

Com a promulgação da Constituição Federal de 1988, o meio ambiente foi tutelado como coisa ou bem jurídico, em consonância com a concepção filosófica antropocêntrica de caris kantiana (KANT, 2003), na qual os animais não humanos e os vegetais não podem figurar como sujeitos de direitos por não serem capazes de exprimir ou comunicar racionalmente a sua vontade e, dessa forma, serem incapazes de contrair direitos e deveres (BOBBIO, 2011). Assim, na interpretação jurídica da redação conferida ao artigo 225 desse documento jurídico superior, o meio ambiente foi considerado como "bem de uso comum do povo" (BRASIL, 1988), enquadrando-se nessa perspectiva formal que caracterizou a formação do Direito moderno. Claramente, vê-se uma opção que não incorpora a ideia de "meio ambiente social" na elaboração do citado dispositivo legal, como se o meio ambiente natural (natureza) fosse um espaço dissociado do meio ambiente social, revelando uma perspectiva utilitarista fomentada por uma razão prática (CANOTILHO, 2001). Não obstante essa dificuldade inicial, a redação conferida a tal artigo atribui ao "Poder Público e à coletividade" o dever de defesa e preservação do meio ambiente ecologicamente equilibrado, tendo por beneficiárias "as presentes e futuras gerações", o que demonstra a dissociação anteriormente aventada, que coloca a natureza a serviço da humanidade (BRASIL, 1988).

Na verdade, o foco deste trabalho não é abordar a problemática em tela a partir de uma análise da hermenêutica constitucional, referente ao valor do Direito Constitucional Ambiental, 
cabe precisar que o processo de conscientização da questão ambiental desde a ótica constitucional, conforme o paradigma consubstanciado na Carta Maior, à primeira vista, não permite que se possa avançar no sentido de ultrapassar os limites estritamente jurídicos e metajurídicos que colocam a natureza como um objeto (bem jurídico) à disposição dos atores sociais. Isso porque a configuração do atual modelo econômico levanta obstáculos à incorporação de formas discursivas marginais ou não-hegemônicas, como é o caso das reivindicações das organizações dos povos originários que não consideram a natureza como um bem econômico a ser explorado sob um viés permanentemente mercadológico (QUIJANO, 2005).

Embora as várias limitações e imposições comissivas de natureza constitucional sejam normas imperativas e, dessa forma, oponíveis juridicamente, dependem da ação política do Estado e dos processos de conscientização social para que tenham eficácia e efetividade (BOBBIO, 2011). Essa perspectiva normativa revela uma problematização acerca dos contornos políticos inerentes à interpretação do Direito, no que toca à possibilidade de uma hermenêutica construída democraticamente, trazendo à tona o exame crítico da dogmática jurídica, porque propõe novas formas de percepção do fenômeno jurídico. De fato, a gestão do atual modelo regulatório do meio ambiente pressupõe a configuração constitucional da democracia participativa, quando o dever de preservação ambiental se divide entre o Estado (democracia representativa) e a Sociedade (democracia participativa). Significa dizer que se descortina uma possibilidade de confrontação entre os anseios políticos consagrados na Carta Política brasileira e os interesses econômicos da nova lex mercatoria (SOUSA SANTOS, 2002 b), que atinge em cheio o atual sistema mundo de produção capitalista predatório. ${ }^{6}$

\footnotetext{
${ }^{6}$ Por força dos dispositivos constitucionais que estabelecem o direito de propriedade, há clara limitação a esse direito, fundado nos valores ecológicos ou socioambientais (FENSTERSEIFER, 2008). Assim, a vinculação desse direito patrimonial à função social é uma forma de limitar a exploração mercantil da propriedade privada no mercado de capitais, que promove a regulamentação desse ativo (a propriedade imobiliária), remetendo-o à legitimação que atenda aos requisitos da preservação das áreas verdes, por meio de critérios de preservação estabelecidos no capítulo referente aos direitos fundamentais (BRASIL, 1988, artigo $5^{\circ}$, inciso XXIII); e dos que regulam a política agrícola e fundiária e tutelam a propriedade rural (BRASIL, 1988, artigo 186, incisos I e II). No que tange à propriedade urbana, há disposição expressa ao equilíbrio do meio ambiente social, quando a mesma função social indica, como critério ao gozo desse direito, o adequado uso e ocupação do solo (BRASIL, 1988, artigo 182). Nesse aspecto, a reformulação do Código Civil (BRASIL, 2002) acompanha a regulamentação constitucional, estabelecendo, no $\S 1^{\circ}$ do artigo 1.228 que o direito à propriedade "[...] deve ser exercido em consonância com suas finalidades econômicas e sociais e de modo que sejam preservados, de conformidade com o estabelecido em lei especial, a flora, a fauna, as belezas naturais, o equilíbrio ecológico e o patrimônio histórico e artístico". No que respeita às limitações ao direito de propriedade dos povos nativos, assegurou-se o seu direito a terra, no que isso seja garantidor de seu respeito à vida, à cultura e ao seu bem-estar, mas havendo cláusula que autoriza a União a promover a exploração dos recursos hídricos e minerais, "ouvidas às comunidades afetadas" (BRASIL, 1988, artigo 231, $3^{\circ}$ ).
} 
Segundo Frederick H. Buttel (2001), a Sociologia dos Recursos Naturais era o ramo de estudos socioambientais predominante nas ciências sociais até finais dos anos 1970, destacando-se entre as doutrinas que então se dispunham a refletir sobre as questões ambientais, embora tenha surgido de forma exógena ao movimento ambientalista, com uma abordagem singular do desgaste ambiental acumulado ao longo de vários ciclos produtivos, voltada à análise da poluição e da escassez de recursos com a consequente racionalização e reutilização de matérias primas. Essa mesma abordagem não privilegiava o papel dos movimentos sociais ambientalistas, mas observava o meio ambiente por meio de uma leitura extremamente teórica e meta-teórica, a partir de uma concepção estatista concentradora.

Em substituição a essa abordagem, despontou a Sociologia Ambiental, nos finais dos anos 1970 e começo dos 1980, com uma proposta derivada da observação da interação entre as dimensões sociocultural e socioambiental: por conta de uma percepção do papel humano na transformação do meio ambiente, trazendo à tona a importância da análise conservacionista, relacionada com os ecossistemas locais e paisagísticos, com a exploração a longo prazo, de maneira sustentável e com a divisão racional dos recursos naturais, por meio de uma gestão compartilhada da natureza com seu entorno social (BUTTEL, 2001).

Retornando ao paradigma constitucional hegemônico e antropocêntrico, mesmo que se considere que o modelo capitalista promova a proteção ambiental por meio da redução de riscos, impondo multas e indenizações reparatórias em casos de danos ambientais, deve-se também considerar que ele promove uma deturpação da ideia de proteção, pela criação do chamado "mercado do carbono", no qual se negociam coeficientes de poluição entre os Estados, no plano internacional, mercantilizando os processos de contaminação ambiental. Esse mercado do carbono revela a lógica interna do sistema econômico, que trabalha sobre a concepção mercantil que privilegia preço e mercado, desprezando valores socioculturais que não sejam aptos à absorção por essa racionalidade.

Exemplo disso se revela na regulamentação do princípio jurídico do "poluidor pagador", derivado da ideia do mercado de carbono instituído pelos tratados internacionais (CANOTILHO, 2001). Todavia, em contraposição a isso, não há como dissociar o meio ambiente como espaço de desenvolvimento da subjetividade humana e das suas formas de percepção/cognição, principalmente no que toca às experiências sociais com a Terra. No esteio dessas ideias, a formação de uma cultura ecológica ficará a depender de uma educação ambiental que possa revelar a percepção que a sociedade civil tenha da natureza, ao passo em que possa aprofundar e, nos casos de utilização predatória, mudar a forma como a natureza é 
utilizada, como orienta a concepção de dialogicidade freiriana de ensino: com respeito aos saberes e autonomia dos educandos (FREIRE, 1996). Essa abordagem pedagógica integra, de maneira indelével, a concepção jurídico-política do atual modelo de organização política, vez que o artigo $225, \S 1^{\circ}$, inciso VI impõe que é dever do Estado “[...] promover a educação ambiental em todos os níveis de ensino e a conscientização pública para a preservação do meio ambiente" (BRASIL, 1988), e visto que a educação é o esteio pelo qual o indivíduo poderá desenvolver o seu potencial pessoal, preparar-se para uma vida cidadã e adquirir competências para o trabalho, nos termos do artigo 205 da Carta Política (BRASIL, 1988).

\section{A EDUCAÇÃO AMBIENTAL E SEUS IMPASSES EPISTEMOLÓGICOS}

Para fins desta reflexão, convém esclarecer que o termo "conscientização" pode ser interpretado de forma a descrever como o intelecto humano lida com o conhecimento e a ação, na construção de uma realidade pensada. Esse conceito remete o investigador à noção de uma consciência-de-si, que denota uma clivagem entre seres humanos e animais, diante da racionalidade que torna possível aos homens serem conscientes e construtores de sua realidade. É em busca dessa percepção do ser-no-mundo que a conscientização se converte em " [...] um teste de realidade. Quanto mais conscientização, mais se 'des-vela' a realidade, mais se penetra na essência fenomênica do objeto, frente ao qual nos encontramos para analisá-lo" (FREIRE, 1979, p. 26). Essa indicação demanda não a ação ideal de um intelecto que presume ou que constrói o conhecimento de um plano ideal, puramente lógico-dedutivo, mas de um intelecto que se alia à práxis, fazendo da conscientização a síntese dialética entre ação e reflexão (FREIRE, 1979).

A formulação e busca de uma conscientização ambiental deveria se transformar em um mecanismo popular de defesa dos interesses ecológicos, na perspectiva de privilegiar uma construção de saberes consonante com o sentir de todas as etnias originárias, para o qual se requer um trabalho alicerçado desde as leituras simbólicas e que reflita o imaginário desses atores sociais não-estatais. Diz-se isso na medida em que as regulações constitucionais que tutelam o ensino público fundamental, médio e superior atribuem uma gestão partilhada entre as instituições de ensino, de um lado, e as comunidades, de outro (BRASIL, 1988, artigo 205), com o pluralismo de ideias e concepções pedagógicas (BRASIL, 1988, artigo 206, inciso III) que podem ser construídas por meio da interconexão entre teoria e prática. Essa leitura sistemática da Constituição Federal abre espaço para a propositura de projetos pedagógicos 
voltados à criação de uma cultura ambiental que dê passo a um novo sentido comum em torno dos direitos da natureza. Esse deslocamento prático-teórico proporcionaria uma obliteração da concordata existente entre os ocupantes do Poder estatal e os do Poder Econômico que vêm se apropriando da natureza em prol de interesses meramente mercantis?

A diferença que existe entre uma abordagem que privilegia o ator público estatal e outra centrada no ator privado, cuja procedência é oriunda das organizações da sociedade civil, marcará a centralidade do sujeito político responsável pelo processo de mudanças sociais, cujo predomínio, notadamente no caso brasileiro, é ainda assumido pelo ator estatal que se converte em sujeito público no cenário político amplo. Assim, todas as vezes que se demandam políticas públicas para a proteção do meio ambiente, via de regra, a sociedade civil omite-se de assumir uma liderança nesse processo social, perdendo, conseguintemente, qualquer protagonismo social em relação às disputas políticas existentes na cena em que os atores interagem.

A exposição da crítica socioeconômica que se coloca contra o sistema de produção industrial pode ser o substrato no qual se constrói a conscientização sobre a questão ecológica. Isso quer dizer que, revelando a lógica interna desse sistema de produção e o tratamento por ele conferido ao meio ambiente (sociocultural e natural), com o aporte das experiências sociais marginalizadas acerca dos processos de transformação do espaço natural-social, podem ganhar voz outras formas de percepção sobre como preservar o meio ambiente. Se atualmente as propostas de ação humana no meio ambiente lidam com a manutenção dos resíduos (reduzir, reutilizar, reciclar e reeducar), pode ser que uma participação social seja ampliada aos povos nativos e que isso mude o foco do debate para outras perspectivas, ainda silenciadas.

Nesse diagrama teórico, cobra relevância os debates sobre a intensidade de participação dos movimentos sociais no aprofundamento das perspectivas ecológicas do mainstream acadêmico-institucional, vez que propõem uma abordagem mais ampla sobre a problemática socioambiental. Existem fortes indicações de que a gestão democrática do ensino de temas ambientais poderia ser executada nos moldes da proposta freireana de conscientização. Destarte, convém explicitar que a Lei de Diretrizes e Bases da Educação - LDB (Lei n ${ }^{\circ}$ 9.394/1996) regulamenta um plano participativo nas escolas públicas, que permite o engajamento dos movimentos sociais e organizações da sociedade civil nos processos educativos. Todavia, existe uma larga distância entre a prescrição normativa e a eficácia/efetividade das propostas legislativas, que se encontra vinculada em larga medida à adesão popular e governamental. É por essa razão que o Plano Nacional de Educação regulamentado pela LDB prevê duas linhas de ação, que se compõem entre (i) um plano de 
participação das comunidades escolar e local (BRASIL, 1996, artigo 14, inciso II), e (ii) um plano de formação que contemple o ensino da História do Brasil com a inserção do ensino da formação do povo brasileiro que englobe as "[...] matrizes indígena, africana e europeia" (BRASIL, 1996, artigo 26, $4^{\circ}$ ), possibilitando o aprendizado das línguas dos povos autóctones (BRASIL, 1996, artigo 32, $\S 3^{\circ}$ ).

No que respeita a participação dos atores sociais na construção do saber, na LDB existe uma diferenciação quanto ao ensino dos povos autóctones, que se converte numa oferta escolar bilíngue das ciências "das demais sociedades indígenas e não-índias", com o objetivo de resgatar suas identidades e memória histórica e conhecimentos culturais (BRASIL, 1996, artigo 78, inciso II). A lei em questão dispõe de um modelo de ensino intercultural que promova uma conscientização dos povos "não-índios" quanto aos saberes dos povos originários? Se houver uma forma de educação ambiental que promova o reconhecimento dos saberes acumulados pelos movimentos sociais e organizações dos povos originários - reveladora de suas práticas alternativas de interação com a natureza - seria possível se desenhar uma nova abordagem sobre os riscos das atividades produtivas? Neste caso, poderia haver a construção de "“[...] uma nova gramática social e cultural e o entendimento da inovação social articulada com a inovação institucional, isso é, com a procura de uma nova institucionalidade da democracia" (SOUSA SANTOS, 2002a, p. 51) ${ }^{7}$. Com os avanços da crítica social, não parece pertinente aplicar o método positivista das ciências naturais nas sociais, quer dizer, promovendo um afastamento entre os juízos de fato e de valor sem, com isso, comprometer o engajamento necessário entre os sujeitos envolvidos na realidade social que estudam e na qual vivem (LOWY, 1978).

Destaca-se que, na condução das políticas públicas estatais de meio ambiente, as atuais formas de participação popular estão centradas em algumas áreas muito reduzidas: (i) pela via judicial, através da ação popular ${ }^{8}$ e (ii) através da coparticipação na definição de campanhas

\footnotetext{
${ }^{7}$ Isso implica a confecção de uma nova concepção democrática não hegemônica, capaz de incorporar formas de reconhecimento da pluralidade humana a partir de um olhar que escape das lógicas formal e tradicional acerca dessa pluralidade, cujo um dos mecanismos de abordagem pode ser a dialogicidade freireana. Paulo Freire já havia detectado essa necessidade, quando orientava os educadores à percepção que seus educandos possuíam uma experiência sentida da realidade que não poderia ser desperdiçada, mas integrada nos discursos dos conhecimentos que lhes eram transmitidos (FREIRE, 1982, 1996).

${ }^{8}$ No campo da exigibilidade de direitos sociais e de preservação do meio ambiente, a Constituição brasileira contempla um instrumento de formulação processual que permite aos cidadãos e suas organizações sociais a propositura de demandas, por meio da ação popular para a defesa de bens e valores ambientais e do patrimônio histórico e cultural da nação (BRASIL, 1988, artigo 5º inciso LXXIII). Porém, essa atribuição legal está diretamente vinculada a um procedimento formal (o processo judicial) que depende de uma decisão final (sentença judicial), momento em que se descortina o aparato burocrático do Poder Judiciário como instância monopolizada pelo Estado e, portanto, é um tipo de participação indireta, pois que depende da palavra final dos órgãos da
} 
educativas de proteção ao meio ambiente, diante do argumento que a educação será promovida e incentivada com a colaboração da sociedade e com a gestão democrática do ensino público (conforme regulação combinada dos artigos 205 e 206 inciso IV do texto constitucional).

\section{A EDUCAÇÃO AMBIENTAL COM SUPORTE NA INTERCULTURALIDADE}

Nos dispositivos normativos anteriormente exemplificados, que cuidam da propriedade privada urbana e rural e tradicional, a prática do Estado brasileiro não contempla a aplicação princípios norteadores dos direitos fundamentais dos povos originários, verbi gratia, os direitos: à consulta prévia, à participação política e social, à interculturalidade e à propriedade, nos moldes de suas próprias tradições socioculturais, conforme proclamam as regulações que ordenam pautas e orientações sobre as maneiras que os atores estatais nacionais devem observar ao formularem políticas públicas nacionais, que são orientadas a abordar as questões relacionadas com os direitos dos povos originários em seus territórios, conforme se verá, posteriormente ${ }^{9}$.

Diante desse argumento, pode-se construir uma metodologia de ensino ambiental que incorpore: a diversidade das identidades culturais no seu núcleo duro estruturante, e que nele aborde as questões históricas, políticas, culturais e sociais dos elementos humanos envolvidos, mas sem desconsiderar a luta e as forças que colocam óbices à constituição das identidades; que indique aos envolvidos no processo de ensino a necessidade de uma aproximação solidária às demandas dos educandos e que se revelam de real importância para eles; e que impeça o retorno de um modelo de educação que colocam os formadores como proprietários de uma verdade autoritária (FREIRE, 1996) ${ }^{10}$.

\footnotetext{
jurisdição. Esse mecanismo, de matriz eminentemente liberal, segue os procedimentos e ritos processuais formais, alheios às práticas e instâncias sociais de reivindicação direta.

${ }^{9}$ Nesse aspecto, é preciso reconhecer os episódios violentos que atingiram povos autóctones na Região Norte do Brasil: (i) no conflito de terra protagonizado pelos exploradores agroindustriais produtores de arroz contra os povos ingaricós, macuxis, patamonas, taurepangues e uapixanas da Terra Indígena Raposa Terra do Sol, e (ii) a da construção da represa de Belo Monte no rio Xingú, que atingem as tribos kayapó, arara, arareute, apidereula, juruna e maracanã.

${ }^{10}$ Essa é uma questão crucial no que respeita ao atual estágio do desenvolvimento da cultura ambiental ainda pouco inclusiva, no contexto de um modelo constitucional que privilegia a cidadania urbana e rural capitalista, mas que trata as populações nativas como sujeito-reificado e subordinado a regulações que, sob a aparência de proteção do Estado, deixa de considerá-lo como um ator social propositivo e detentor de uma cidadania participativa e construtora de um novo discurso político acerca da utilização da Terra, para convertê-lo em um ator subordinado e preso às antigas práticas e imaginários sociopolíticos. É por essa razão que se apela à preservação e à disseminação das experiências dos povos originários, com vista a incorporar a percepção de suas tribos sobre a relação homem-natureza no discurso das políticas públicas, nomeadamente, na política de educação ambiental, pois, afinal, a participação democrática é um somatório de formas de percepção de mundo para o enfrentamento de lógicas que se colocam contrárias à continuação da vida em comunidade.
} 
O estudo em torno do tema do multiculturalismo indica que as políticas indigenistas até aqui desenvolvidas pelo Estado brasileiro converteram-se (elas mesmas) numa característica existencial do multiculturalismo brasileiro, sendo determinante no grau de intensidade democrática e da cidadania entre as diferentes culturas ${ }^{11}$. Confrontá-las, portanto, torna inevitável uma conscientização ambiental que se aperceba da dialética existente entre os atos de denunciar a estrutura desumanizante e de anunciar a estrutura humanizante, sendo essa a razão pelo que se conclui que "a utopia é também um compromisso histórico" (FREIRE, 1979, p. 27).

De fato, a malha social brasileira enfrenta uma questão multicultural bem diversa daquela existente nos países do centro do sistema mundo de produção capitalista. Nesse centro, que costuma ser identificado como os países do Norte global, essa questão também exige uma abordagem diversa daquela que usualmente se dá nessa temática, conforme ela se constituiu em diferentes movimentos migratórios de grupos humanos em direção a esse espaço (REX, 1995). No caso brasileiro, observa-se o problema do multiculturalismo desde uma ótica pós-colonial, na qual os assentamentos dos povos invasores solidificaram-se, quer por um processo de extermínio, quer por um de assimilação dos povos originários das terras ocupadas.

No que toca às comunidades autóctones e seu contato com os povos urbanos e rurais ocidentalizados, no processo de tessitura da malha social que pode ser chamada de "esfera comunal" (TIRYAKIAN, 2003, p. 22), cumpre reflexionar sobre a substantivação desses povos na formação dos discursos políticos e práticas sociais na história moderna da atual República. E nesse contexto, desde a segunda metade do século XIX que se promoveu a sua invisibilização, quer na literatura, quer nas práticas políticas do Estado, como se pode observar no indianismo literário que se propunha à reutilização da imagem idealizada do "índio" da poesia clássica portuguesa: o "índio" não era um ser social presente, mas preso ao passado colonial (PUNTONI, 2003, p. 635).

Entretanto, a utilização do substantivo "índio" denota uma conceptualização discriminatória, porquanto obedece ao fato de que o empreendimento da descoberta do "Novo Mundo" unificou em uma só designação todos os povos que habitavam esses territórios conquistados, vez que os objetivos iniciais do projeto de conquista e expansão marítima europeia era de encontrar novas rotas de acesso ao mercado da Índia. Por essa razão, tanto o

\footnotetext{
${ }^{11}$ Desta feita, emerge o estabelecimento de uma nova utopia social, que reconstrua novas relações sociais baseadas em práticas culturais que potencializem o cenário das relações entre o meio ambiente e as populações originárias, e entre estas últimas e as classes subalternas, em simbiose com as formas dominantes de percepção da questão ecológica.
} 
discurso político-ideológico, quanto a historiografia e legislação tratam da questão dos povos das Américas desde uma perspectiva eminentemente eurocêntrica, que não incorpora na sua análise as identidades culturais próprias dos povos nativos (QUIJANO, 2005).

Convém salientar que a Carta Outorgada pelo então imperador, D. Pedro I, de 1824, não fazia sequer menção às comunidades originárias, sendo que a primeira política pública do então formado Estado brasileiro foi executada mediante o Decreto n ${ }^{\circ} 426$ de 1845 (BRASIL, 1845), que tratava do "Regulamento acerca das Missões de catequese e civilização dos índios", normatizando "[...] uma política geral para a questão indígena, a primeira desse o diretório pombalino, revogado em 1798" (PUNTONI, 2003, p. 643). Entretanto, na leitura desses primeiros textos jurídico-políticos imperiais, expressões como "bárbaros" e "selvagens", sem poder ovildar a expressão “civilização dos índios”, acima aventada, indica que eles precisavam ser civilizados - como se não fossem, per si, uma civilização.

É também deste período que se implementa a primeira tentativa de absorção das línguas autóctones, mas com o interesse inequívoco de assimilação ao então projeto de instituição de uma nacionalidade brasileira (PUNTONI, 2003) - que levanta uma dúvida sobre as atuais políticas públicas de educação, nas quais o ensino das línguas originárias poderia ser empregue com o mesmo intuito. ${ }^{12}$ A crítica a essa apropriação da alfabetização política desumanizante pode ser encontrada em Paulo Freire, para quem “[...] o processo de alfabetização política - como o processo linguístico - pode ser uma prática para a 'domesticação dos homens', ou uma prática para a libertação. No primeiro caso, a prática da conscientização não é possível em absoluto" (FREIRE, 1979).

\footnotetext{
${ }^{12}$ Durante a formação republicana brasileira, a questão dos povos nativos ficou sempre à sombra de uma visão paternalista do Estado. O Serviço de Proteção aos Índios e Localização dos Trabalhadores Nacionais - SPILTN (BRASIL, 1910) foi o primeiro programa republicano implantado, logo seguido pela aprovação do Código Civil de 1916 (BRASIL, 1916) que, juridicamente, tratava o "silvícola" como relativamente capazes para atos da vida civil. Tal sistema de "proteção" considerava os "índios" como seres humanos em estado de transição para a civilização, tendo por finaldidade a criação de assentamentos "civilizatórios" que pudessem convertê-los em trabalhadores rurais ou urbanos, e integrá-los à Sociedade e combater o massacre dos povos originários que ocorria na interiorização dos processos produtivos modernos (CARNEIRO DA CUNHA, 1994). Substituindo a SPILTN, surgiu a Fundação Nacional do Índio - FUNAI ${ }^{12}$, no ano de 1967, durante o governo de Castelo Branco, logo na instituição do regime autoritário de exceção. Desde então, a atuação do Estado no tema de políticas de proteção aos povos nativos passou por transformações, tendo abandonado paulatinamente as políticas do multiculturalismo dominante até meados dos anos 1990, na tentativa de desenvolver uma abordagem intercultural que promova a tranformação das culturas por meios de processos de interação. Desde muito tempo que essa fundação recebe severas críticas por não atender de forma eficiente as demandas dos povos originários brasileiros nas questões que envolvem disputas de terras e disseminação de doenças contraídas no contato com os povos ocidentais e ocidentalizados, sendo certo que, com o fim da ditadura civil-militar dos anos 1964-1985, houve uma maior visibilidade desses problemas (AQUINO, 1999).
} 
Nesse diapasão, convém explicitar que, na construção de uma cidadania política, deveria estar inserida uma cidadania ambiental para a proteção das futuras gerações que inclua os povos originários de maneira ativa e participativa. Entretanto, se a cidadania ambiental for promovida de forma centrada num modelo socioeconômico concentrado nas produções rural e urbana, sem contemplar as experiências social e produtiva nativas, haverá um déficit de participação democrática e, consequentemente, uma ausência regulatória na formação política nacional. Isso porque o interculturalismo, como concepção política da diferença, tende a subjugar a perspectiva do multiculturalismo, vez que não incorpora a forma de racismo velada deste último que, por meio da ideia de tolerância, transforma o nativo num "Outro" folclórico, sob o olhar condescendente da percepção eurocêntrica (ŻIŻEK, 2013, p. 157). Além disso, o multiculturalismo seria incapaz de promover uma autêntica mudança política, visto que, enquanto política, acentua e solidifica a diferença por meio da distribuição de papéis que impossibilita uma genuína mobilidade social (SOUSA SANTOS; NUNES, 2003).

Ante as sensíveis dificuldades que se revelam no plano nacional, a nível de regulamentação internacional, cumpre destacar a Convenção 169 da Organização Internacional do Trabalho - OIT (ORGANIZAÇÃO INTERNACIONAL DO TRABALHO, 1989), que instituiu o mecanismo jurídico intitulado “consulta prévia”. Ratificado pelo Brasil por força do Decreto 5.051 de 2004 (BRASIL, 2004), esse tratado internacional estabeleceu o instituto jurídico da consulta-previa como uma ferramenta de participação direta que se converteu num direito fundamental dos povos nativos brasileiros, e que se traduz numa diretiva de desenvolvimento que lhes confere a possibilidade de opinar sobre obras e atividades a serem realizadas em seus territórios e que venham a lhes causar qualquer tipo de abalo ou prejuízo social, econômico ou cultural. Vez que os tratados internacionais que regulam direitos humanos passam a figurar no rol dos direitos fundamentais da República, por força da disposição legal contida no $§ 3^{\circ}$ do artigo $5^{\circ}$ da Constituição Federal brasileira, o artigo 7 desse Convênio tem força constitucional e figura como cláusula pétrea.

Diante do exposto, faz-se necessário refletir sobre o estado atual do constitucionalismo brasileiro em relação ao paradigma do Estado Constitucional Ecológico e suas implicâncias sobre as atividades dos agentes econômicos e sociais nacionais. Em vista do processo de ensino que promova uma conscientização ambiental inclusiva/intercultural, um dos vários caminhos que se poderia trilhar coloca o investigador diante da Política Nacional de Educação Ambiental.

Validar a hipótese de que houve a participação dos povos originários na elaboração e discussão dos projetos das escolas municipais cearenses que participaram da IV CNIJMA de 
2013. Supõe-se que os projetos pedagógicos que integram a Política Nacional de Educação Ambiental abordaram a perspectiva autóctone e podem se converter em um meio para superar a visão folclórica em relação aos grupos intitulados genericamente como "indígenas", como via de construção a uma interculturalidade (ŻIŻEK, 2003).

$\mathrm{Na}$ investigação que fundamenta este trabalho, foi possível identificar, no Estado do Ceará, os seguintes povos nos respectivos municípios ${ }^{13}$ : os tapebas, no Município de Caucaia; os tremembés, nos municípios de Itarema e Itapipoca; os pitaguarys, no Município de Pacatuba e os kariris, nos municípios de Pereiro e Barbalha. Destaca-se que, nos municípios identificados, os de Itarema e Caucaia pertencem à Região Metropolitana de Fortaleza, quarta capital do país em número de habitantes, e que os povos designados convivem com a população ocidental, quer porque foram expulsos de suas terras, quer porque procuraram se integrar-se ao modo de vida urbano.

Isso posto, analisou-se de que forma os projetos foram concebidos pelos professores formadores que participaram do IV CNIJMA, verificando se houve ou não a participação dos nativos na temática ambiental, vez que esses projetos foram utilizados na formação dos estudantes de nível fundamental (básico), considerados no campo de intervenção da Política Nacional de Educação Ambiental.

No caso do Estado do Ceará, de acordo com o levantamento efetuado, somente as seguintes escolas trataram da temática dos povos originários:

\begin{tabular}{|l|c|c|}
\hline \multicolumn{1}{|c|}{ ESCOLA } & MUNICÍPIO & ETNIA \\
\hline Escola de Ensino Fundamental Antonieta Cals de Oliveira & Pereiro & Kariri \\
\hline $\begin{array}{l}\text { Escola de Ensino Fundamental Senador Martiniano de } \\
\text { Alencar }\end{array}$ & Barbalha & Kariri \\
\hline $\begin{array}{l}\text { Colégio Santo Antônio (CSA) - confessional (católico; } \\
\text { instituição privada) }\end{array}$ & Barbalha & Kariri \\
\hline Escola de Ensino Fundamental Maria de Sa Roriz & Pacatuba & Pitaguary \\
\hline $\begin{array}{l}\text { Escola Diferenciada de Ensino Infantil e Fundamental Abá } \\
\text { Tapeba }\end{array}$ & Caucaia & Tapeba \\
\hline Escola de Ensino Fundamental Monsenhor Tabosa & Itapipoca & Tremembé \\
\hline Escola Indígena Narciso Ferreira Matos & Itarema & Tremembé \\
\hline
\end{tabular}

À guisa de análise quantitativa e qualitativa, como se pode perceber da coleta do material catalogado pela Conferência, dentre as escolas acima referidas, as únicas que apresentaram projetos genuinamente "indígenas" foram a Escola Indígena Narciso Ferreira Matos (Itarema) e a Escola Diferenciada de Ensino Infantil e Fundamental Abá Tapeba

\footnotetext{
${ }^{13}$ Todas as referências às etnias dos povos originários do Estado do Ceará foram colhidas no site da Internet do Instituto de Pesquisa e Estratégia Econômica do Ceará (CEARÁ, 2006).
} 
(Caucaia). Ambas tiveram como esteio pedagógico o projeto "Mãos na Terra", que trata da medicina tradicional com a utilização de plantas e conhecimentos autóctones no tratamento de doenças orgânicas. Ainda, e muito relevante acerca dessas duas escolas, foi a utilização de conhecimentos interculturais, tendo em vista a proposta de uma integração entre os conhecimentos nutricionais ocidentais e os hábitos alimentares tradicionais dos povos tremembés (Itarema) e tapebas (Caucaia).

Nesse ínterim, é preciso revelar que a E.I.F. Abá Tapeba apresentou, ainda, um outro projeto, de cariz mais sociopolítico, orientado pela professora Selma Teixeira Cunha e intitulado "Terra, plantio, espaço e vivência". Nesse documento, é feita uma espécie de declaração de intenções políticas, na qual os povos tabebas reivindicam o seu direito sagrado às terras em que habitam, criticando abertamente o Estado brasileiro - tanto sob o enfoque da inexistente reforma agrária, quanto da ineficiência na demarcação das terras "indígenas". É um projeto educacional flagrantemente conhecedor do tema das gerações futuras - não apenas por citá-lo explicitamente, mas pela incorporação de métodos específicos de cultivo adquiridos pela experiência nativa. Assim, revelando uma preocupação genuína com a sobrevivência de seus direitos culturais e de ocupação de suas terras tradicionais, a Escola Abá Tapeba levanta um problema que atinge todos os povos tradicionais que encontram-se no território do Estado do Ceará, como se verá, a seguir.

De acordo com o último senso demográfico realizado pelo Instituto Brasileiro de Geografia e Estatística (IBGE), de um total de 20.697 nativos, no Ceará existem 2.988 vivendo em terras indígenas ${ }^{14}$ e 17.709 assentados fora de terras indígenas (IBGE, 2010). Um dos casos mais emblemáticos, envolvendo disputas de terras, está o caso do Município de Caucaia, no qual a nação tapeba foi removida dos seus territórios originais e realocada fora do perímetro urbano da cidade. Até o momento, a Terra Indígena anacé, tradicionalmente ocupada pelos tapebas, encontra-se em fase de estudo junto aos órgãos indigenistas responsáveis pelo processo de demarcação, abrigando nove aldeias. Enquanto a Terra Indígena Córrego João Pereira, da etnia Tremembé (no Município de Acaraú) encontra-se a 23 quilômetros de distância da Terra Indígena de Tremembé de Almofala, em Itarema, em cujo sítio encontra-se a escola de ensino diferenciada acima aludida, as aldeias de Itapipoca localizam-se na Terra Indígena de Tremembé da Barra do Mundaú. Os povos tradicionais de Pacatuba, por sua vez, encontram-se em terras demarcas e reconhecidas e dispõe de ensino diferenciado.

\footnotetext{
${ }^{14}$ Todas as referências às terras indígenas aqui abordadas foram recolhidas diretamente do site de Internet da FUNAI (FUNDAÇÃO NACIONAL DO ÍNDIO, 2015).
} 
Em comparação com as nações autóctones acima delimitadas, deve-se mencionar que a situação das tribos kariris é duplamente intrigante: (i) não possuem terras demarcadas, em decorrência do esfacelamento de sua organização social, que teve início na "Guerra dos Bárbaros" do século 18 e que perdurou com as políticas de ocupação do interior do Estado do Ceará; (ii) não são reconhecidos pelo governo do Estado como povos originários, vez que não estão cadastrados na Fundação Nacional de Saúde - FUNASA (MAIA, 2009, p. 66). O que torna uma pesquisa em ciências sociais autenticamente científica é a constatação de que a realidade não é transparente. A aparência e a essência são duas categorias distintas, que dependem da interpretação dada pelo observador, constituída por meio de sua reflexão (FREIRE, 1979, 1996; SOUSA SANTOS, 1995, 2002b) ${ }^{15}$. É neste sentido que será avaliada a política pública de educação ambiental apresentada neste projeto: a partir de uma perspectiva que entende ser necessária a participação de todos os atores sociais, no processo de construção de uma conscientização ecológica (FREIRE, 1979, 1996; SOUSA SANTOS, 2002a; QUIJANO, 2005; LOWY, 1978). Isso para se afirmar que, tirando as duas escolas acima citadas, todas as outras abordaram o tema "indígena" de forma caricaturada.

\section{CONCLUSÃO}

A proposta de uma releitura do papel do Estado contemporâneo passa, necessariamente, pela análise da sustentabilidade dos processos socioeconômicos, culturais e ambientais. Isso porque, como pessoa jurídica de direito público, o Estado visa concretizar os processos políticos intestinais que derivam das dinâmicas heterogêneas de uma sociedade complexa, como a brasileira. A nossa formação étnico-cultural traz uma problemática específica no campo da conservação ambiental, posto que coabitam duas perspectivas soberanas no solo brasileiro: a dos povos originários, cujo paradigma é a relação com os valores e bens da natureza, na formatação de suas representações imaginárias e simbólicas, de maneira interdependente; e a da sociedade brasileira ocidentalizada, cujo modelo de interação ambiental está determinado pelas práticas mercantis, do qual depende a sua estruturação societária e de consumo.

\footnotetext{
${ }^{15}$ Ao que tudo indica, parece muito viva a orientação de Michael Lowy (1978) acerca não apenas do método, mas dos interesses e das inclinações ideológicas que se inserem nos métodos e nas perspectivas de abordagem científica, que estão condicionadas em todos os momentos da pesquisa científica, desde a escolha do objeto de estudo, da interpretação dos fatos e da formulação das teorias.
} 
O modelo de Estado Constitucional Ecológico abre uma porta para o diálogo entre essas duas perspectivas e projetos de vida societários, de maneira a que ambas possam se reconhecer como sujeitos sociais, de forma tal que se construa um equilíbrio entre essas sociedades, ou entre esses conhecimentos e práticas diversificados; a ideia é que, no contato entre elas, não haja uma sobredeterminação ou submissão de uma em relação à outra. Isso porque, na concepção a ser construída dialogicamente, o objetivo final é a sustentabilidade do capital socioambiental, a continuidade da vida planetária, por meio de uma exploração que atente aos limites naturais que a própria natureza é capaz de suportar.

Para que isso possa acontecer, é preciso incorporar dois tipos de aprendizado diferenciados: (1) um de conscientização, na qual os educandos tomem conhecimento não só dos limites da exploração dos recursos ecológicos, mas de outras concepções de mundo, como a dos povos originários e de sua relação com o mundo e; (2) um novo modelo de interpretação jurídica que, com base nas normas jurídicas já consagradas no Texto Maior vigente, encontre o esteio à limitação regulatória do mercado de produção e consumo de bens e serviços frente aos recursos ecológicos nos mecanismos da participação dos povos originários e da formação educacional.

Portanto, eis o busílis epistemológico sobre o qual uma nova forma deontológica deve emergir: a norma jurídica como garantidora não apenas dos direitos do homem, mas, também, da Terra e da natureza. Como elemento ontológico, o Direito deve refletir essa pluralidade que dá forma à sociedade brasileira (visivelmente complexa), de forma a dar voz a novos imaginários sociais, construídos a partir da dialética existente entre os povos que configuram a nacionalidade brasileira, promovendo, assim, a inclusão social materializada no texto constitucional vigente. Ainda, isso seria uma mais valia no que tange à proteção ambiental, tendo em vista a ampliação do paradigma protecionista, pela consideração da cosmovisão dos povos nativos brasileiros.

\section{BIBLIOGRAFIA}

AQUINO, M. A. D. Censura, imprensa e Estado autoritário (1968-1978): o exercício cotidiano da dominação e da resistência: O Estado de São Paulo e Movimento. Bauru: EDUSC, 1999.

BOBBIO, N. Teoria geral do Direito. Tradução: Denise Agostinetti. São Paulo: Martins Fontes, 2011.

BONAVIDES, P. Ciência política. 10. ed. São Paulo: Malheiros, 2000. 
Teoria constitucional da democracia participativa: por um direito constitucional de luta e resistência, por uma nova hermenêutica, por uma repolitização da legitimidade. São Paulo: Malheiros, 2001.

BRASIL. Poder Executivo. Constituição da República Federativa do Brasil de 1988. In: Legislação. Constituição. Brasília, DF, 5 out. 1988. Disponível em: http://www.planalto.gov.br/ccivil_03/constituicao/constituicao.htm. Acesso em: 13 mai. 2015.

Poder Executivo. Decreto $\mathrm{n}^{\mathrm{o}}$ 5.051, de 19 de abril de 2004. Promulga a Convenção no 169 da Organização Internacional do Trabalho - OIT sobre Povos Indígenas e Tribais. In: Legislação. Decretos. Brasília, DF, 19 abr. 2004. Disponível em: http://www.planalto.gov.br/ccivil_03/_ato2004-2006/2004/decreto/d5051.htm. Acesso em: 12 jul. 2015.

Poder Executivo. Lei $n^{\circ} 3.071$, de $1^{\circ}$ de janeiro de 1916. Código Civil dos Estados Unidos do Brasil. In: Legislação. Leis. Rio de Janeiro, RJ, 1 jan. 1916. Disponível em: http://www.planalto.gov.br/ccivil_03/leis/L3071.htm. Acesso em: 12 jul. 2015.

Poder Executivo. Lei $\mathrm{n}^{\mathrm{o}}$ 10.406, de 10 de janeiro de 2002. Institui o Código Civil. In: Legislação. Leis. Brasília, DF, 10 jan. 1916. Disponível em: http://www.planalto.gov.br/ccivil_03/leis/2002/L10406.htm. Acesso em: 12 jul. 2015.

Poder Executivo. Decreto no 8.072, de 20 de junho de 1910. Crêa o Serviço de Protecção aos Indios e Localização de Trabalhadores Nacionaes e approva o respectivo regulamento. In: Legislação. Decreto. Rio de Janeiro, RJ, 24 jun. 1845. Disponível em: http://www2.camara.leg.br/legin/fed/decret/1824-1899/decreto-426-24-julho-1845-560529publicacaooriginal-83578-pe.html. Acesso em: 12 jul. 2015.

Poder Executivo. Lei $\mathrm{n}^{\circ}$ 9.394, de 23 de dezembro de 1996. Estabelece as diretrizes e bases da educação nacional. In: Legislação. Leis. Brasília, DF, 23 dez. 1996. Disponível em: http://www.planalto.gov.br/ccivil_03/LEIS/L9394.htm. Acesso em: 30 jun. 2015.

Poder Legislativo. Decreto $\mathrm{n}^{\mathrm{o}}$ 426, de 24 de Julho de 1845. Contêm o Regulamento ácerca das Missões de catechese, e civilisação dos Indios. In: Legislação. Rio de Janeiro, RJ, 24 jun. 1845. Disponível em: http://www2.camara.leg.br/legin/fed/decret/18241899/decreto-426-24-julho-1845-560529-publicacaooriginal-83578-pe.html. Acesso em: 12 jul. 2015.

BUTTEL, F. H. Environmental Sociology and the Sociology of Natural Resources: Institutional Histories and Intellectual Legacies. Society and Natural Resources, v. 15, n. 3, p. 205-211, 2002.

CANOTILHO, J. J. G. Estado Constitucional Ecológico e democracia sustentada. Revista do Centro de Estudos de Direito do Ordenamento, do Urbanismo e do Meio Ambiente, Coimbra, p. 9-16, Fevereiro 2001. Disponivel em: http://hdl.handle.net/10316.2/5732. Acesso em: 06 jun. 2015. 
CARNEIRO DA CUNHA, M. O futuro da questão. Instituto de Estudos Avançados da Universidade de São Paulo, São Paulo, v. 4, n. 10, p. 121-136, set./dec. 1994.

CEARÁ. Instituto de Pesquisa e Estratégia Econômica do Ceará. Marco Referencial dos Povos Indígenas do Estado do Ceará. Fortaleza, 2006. 33 p. Disponível em: http://www2.ipece.ce.gov.br/SWAP/swapii/salvaguardas/marco_logico_indigenas.pdf. Acesso em: 13 mai. 2015.

FENSTERSEIFER, T. Direitos fundamentais e proteção do meio ambiente: a dimensão ecológica da dignidade humana no marco jurídico-constitucional do Estado Socioambiental de Direito. Porto Alegre: Livraria do Advogado, 2008.

FOSTER, J. B. Marx's Ecology - Materialism and Nature. New York: Monthly Review Press, 2000.

FREIRE, P. Conscientização: teoria e prática da liberdade: uma introdução ao pensamento de Paulo Freire. Tradução: Kátia de Melo e Silva e Benedito Eliseu Leite Cintra. São Paulo: Cortez \& Moraes, 1979.

e Terra, 1982

Ação cultural para a liberdade e outros escritos. 6. ed. Rio de Janeiro: Paz

. Pedagogia da autonomia: saberes necessários à prática educativa. 10. ed. São Paulo: Paz e Terra, 1996.

FUNDAÇÃO NACIONAL DO ÍNDIO. Índios no Brasil. Terras Indígenas. 2015. Disponível em: http://www.funai.gov.br/index.php/indios-no-brasil/terras-indigenas. Acesso em: 13 mai. 2015.

GIL, A. C. Estudo de caso: fundamentação científica - subsídios para coleta e análise de dados - como redigir o relatório. São Paulo: Atlas, 2009.

HORVATH, M. V. F. Direito Administrativo. 2. ed. Barueri: Manole, 2011.

IBGE - INSTITUTO BRASILEIRO DE GEOGRAFIA E ESTATÍSTICA. Censo demográfico 2010. Distribuição espacial da população indígena. In: Fundação Nacional do Índio. 2013. Disponível em: http://www.funai.gov.br/arquivos/conteudo/ascom/2013/img/12Dez/encarte_censo_indigena_02\%20B.pdf. Acesso em: 13 mai. 2015.

KANT, I. A metafísica dos costumes. Tradução: Edson Bini. São Paulo: Edipro, 2003.

LOWY, M. Método dialético e teoria política. Tradução: Reginaldo Di Piero. 2. ed. Rio de Janeiro: Paz e Terra, 1978.

A teoria do desenvolvimento desigual e combinado. Revista Outubro, Instituto de Estudos Socialistas, v. 1, n. 1, p. 73-80, São Paulo, 1988. 
MAIA, Lígio de Oliveira. Índios a serviço D’El Rey: manutenção da posse das terras indígenas durante o avanço da empresa pastoril no Ceará (C.1680-1720). In: PALITOT, ESTÊVÃO MARTINS (Org.). Na mata do sabiá: contribuições sobre a presença indígena no Ceará. 2. ed. Fortaleza: Secult / Museu do Ceará / IMOPEC, 2009. p. 61-86.

MARX, K. O capital. Livro I - O processo de produção do capital. Tradução: Rubens Enderle. São Paulo: Boitempo, 2007.

DESLANDES, S. F.; GOMES, R.; MINAYO, M. C. S. (Org.). Pesquisa social: teoria, método e criatividade. 28. ed. Petrópolis: Vozes, 2009.

ORGANIZAÇÃO INTERNACIONAL DO TRABALHO. Convenção nº 169 - Sobre Povos Indígenas e Tribais. In: Convenções. Genebra, Suiça, 7 jun. 1989. Disponível em: http://www.ilo.org/brasilia/conven\%C3\%A7\%C3\%B5es/WCMS_236247/lang--pt/index.htm. Acesso em: 11 jul. 2015.

PUNTONI, P. O Sr. Varnhagen e o patriotismo caboclo: o indígena e o indianismo perante a hisoriografia brasileira. In: JANCSÓ, I. (Org.). Brasil: formação do Estado e da nação. São Paulo: Editora HUCITEC, 2003. p. 633-675.

QUIJANO, A. Colonialidade do poder, eurocentrismo e América Latina. In: LANDER, E. (Org.). A colonialidade do saber: eurocentrismo e ciências sociais. Perspectivas latinoamericanas. Colección Sur Sur. Buenos Aires: CLACSO, 2005. p. 227-278.

REX, J. Multiculturalism in Europe and America. Nations and Nationalism, Warwick, v. 1, n. 2, p. 243-259, 1995.

SANTOS, M. A Natureza do Espaço: técnica e tempo. Razão e emoção. 4. ed. São Paulo: Editora da Universidade de São Paulo, 2006.

SMITH, N. Desenvolvimento desigual. Rio de Janeiro: Bertrand Brasil, 1988.

SOUSA SANTOS, B. Toward a New Common Sense: Law, Science and Politics in the Paradigmatic Transition. Vol. 1. Londres: Routledge, 1995.

Para ampliar o cânone democrático. In: SOUSA SANTOS, B. (Org.). Democratizar a democracia: os caminhos da democracia participativa. Rio de Janeiro: Civilização brasileira, 2002a.

A crítica da razão indolente: contra o desperdício da experiência - Para um novo senso comum: a ciência, o direito e a política na transição paradigmática. Vol. 1. 4. ed. São Paulo: Cortez, 2002b.

A filosofia à venda, a douta ignorância e a aposta de Pascal. Revista Crítica de Ciências Sociais, Coimbra, v. 80, p. 11-43, 2008. 
SOUSA SANTOS, B.; NUNES, J. R. Introdução: para ampliar o cânone do reconhecimento, da diferença e da igualdade. In: SOUSA SANTOS, B. (Org.). Reconhecer para libertar: os caminhos do cosmopolitismo multicultural. Rio de Janeiro: Civilização Brasileira, 2003. p. 2568.

TIRYAKIAN, E. A. Assessing Multiculturalism Theoretically: E Pluribus Unun, Sic et Non. International Journal on Multicultural Socieities (IJMS), Paris, v. 5, n. 1, p. 20-39, 2003. Disponivel em: http://www.unesco.org/shs/ijms/vol5/issue1/art2. Acesso em: 29 dez. 2014.

ŻIŻEK, S. Multiculturalismo, o la lógica cultural del capitalismo multinacional. In: GRÜNER, E. (Org.). Estudios culturales. Reflexiones sobre el multiculturalismo. Buenos Aires: Paidós, 2003. p. 137-188. 